\title{
Establishment of CORONET; COVID-19 Risk in Oncology Evaluation Tool to identify cancer patients at low versus high risk of severe complications of COVID-19 infection upon presentation to hospital
}

R.J. Lee $\mathrm{PhD}^{1,2 *}$, C. Zhou $\mathrm{PhD}^{3 *}$, O. Wysocki PhD ${ }^{2,3 *}$, R. Shotton $\mathrm{MD}^{1}$, A. Tivey $\mathrm{MD}^{1,2}$, L. Lever $\mathrm{BSC}^{2}$, J. Woodcock BSc${ }^{2}, \mathrm{~A}$. Angelakas $\mathrm{MD}^{4}, \mathrm{~T}$. Aung $\mathrm{MD}^{5}, \mathrm{~K}$. Banfill $\mathrm{MD}^{1,2}, \mathrm{M}$. Baxter MD ${ }^{6}, \mathrm{~T}$. Bhogal $M D^{7,8}, H$. Boyce $M D^{5}$, E. Copson $M D^{9}$, E. Dickens $M D^{10}$, L. Eastlake $M D^{11}, H$. Frost $M D^{3}$, F. Gomes $\mathrm{MD}^{1}$, D.M Graham $\mathrm{PhD}^{1}$, C. Hague $\mathrm{MD}^{1}$, M. Harrison $\mathrm{MD}^{12}$, L. Horsley $\mathrm{PhD}^{1}, \mathrm{P}$. Huddar $\mathrm{MD}^{13}$, Z. Hudson $\mathrm{PhD}^{14}$, S. Khan $\mathrm{MD}^{10,15}$, U. T. Khan $\mathrm{MD}^{7,8}$, A. Maynard MD, $\mathrm{H}^{7}$ McKenzie $M D^{9}, T$. Robinson $\mathrm{PhD}^{14,16}, \mathrm{M}$. Rowe $\mathrm{MD}^{17}$, Anne Thomas $\mathrm{PhD}^{10,15}$, Lance Turtle $\mathrm{PhD}^{18}$, R. Sheehan $\mathrm{MD}^{9}$, A. Stockdale $\mathrm{PhD}^{18}$, J. Weaver $\mathrm{PhD}^{1}$, S. Williams $\mathrm{MD}^{5}, \mathrm{C}$. Wilson $\mathrm{PhD}^{5}$, R. Hoskins $\mathrm{BSC}^{2}$, J. Stevenson $\mathrm{PhD}^{3}$, P. Fitzpatrick $\mathrm{PhD}^{3}, \mathrm{C}$. Palmieri $\mathrm{PhD}^{7,8}$, D. Landers $\mathrm{PhD}^{4}, \mathrm{~T}$ Cooksley $\mathrm{MD}^{1}$, C. Dive $\mathrm{PhD}^{3^{* *}}$, A. Freitas $\mathrm{PhD}^{2,3}{ }^{* *}$, A. C. Armstrong $\mathrm{PhD}^{1,2}{ }^{* *}$

*Equal contribution, ${ }^{* *}$ Equal contribution

1. The Christie NHS Foundation Trust, Wilmslow road, M20 4BX

2. The University of Manchester, Oxford road, M13 9PL

3. Digital experimental cancer medicine and Bioinformatics and Biostatistics teams, Cancer Research UK Manchester Institute Cancer Biomarker Centre, The University of Manchester, Alderley Park, SK10 4TG

4. University Hospitals of Morecambe Bay, Kendal LA9 7RG

5. Weston Park Cancer centre, Sheffield Teaching Hospitals NHS foundation Trust, Sheffield S10 2JF

6. University of Dundee, Dundee DD1 4HN

7. Clatterbridge Cancer Centre, 65 Pembroke Place, Liverpool, L7 8YA

8. The University of Liverpool, Liverpool, L69 3BX

9. Cancer Sciences Academic Unit, University of Southampton and University Hospital Southampton NHS Foundation Trust, Southampton SO16 6YD

10. Leicester Cancer Research Centre, University of Leicester, Leicester, LE2 9LX

11. University Hospitals Plymouth NHS Trust, Plymouth, PL6 8DH

12. Ninewells Hospital, Dundee DD2 1SG

13. Lancashire Teaching Hospitals NHS Trust, Preston PR2 9HT

14. Bristol Haematology and Oncology Centre, Bristol BS2 8ED

15. Oncology Department, University Hospitals of Leicester NHS Trust, Leicester, LE1 5WW

16. Cancer Research UK - Integrated Cancer Epidemiology Programme, University of Bristol. BS8 2BN

17. Sunrise Oncology Centre, Royal Cornwall Hospital, Truro, Cornwall, TR1 3LJ

18. Institute of Infection, Ecological and Veterinary Sciences, University of Liverpool and Tropical and Infectious Diseases Unit, Liverpool University Hospitals 
medRxiv preprint doi: https://doi.org/10.1101/2020.11.30.20239095; this version posted December 3, 2020. The copyright holder for this preprint (which was not certified by peer review) is the author/funder, who has granted medRxiv a license to display the preprint in perpetuity.

It is made available under a CC-BY-NC-ND 4.0 International license .

Keywords: COVID-19, cancer, SARS-CoV-2, decision support tool; CORONET

Word count: 3252

Running title: COVID-19 risk prediction in cancer patients

\section{Correspondence:}

\section{Dr Rebecca Lee}

Department of Medical Oncology

The Christie NHS Foundation Trust

Wilmslow road

Manchester

M20 4BX

Tel: 01614463000

Email: Rebecca.lee-3@manchester.ac.uk

Funding: R. Lee and T. Robinson are supported by the National Institute for Health Research as a Clinical Lecturer. T. Bhogal is supported by the National Institute for Health Research as an academic clinical fellow. U. Khan is an MRC Clinical Training Fellow based at the University of Liverpool supported by the North West England Medical Research Council Fellowship Scheme in Clinical Pharmacology and Therapeutics, which is funded by the Medical Research Council (Award Ref. MR/N025989/1). The Liverpool Experimental Cancer Medicine Centre for providing infrastructure support (Grant Reference: C18616/A25153) and The Clatterbridge Cancer charity (North West Cancer Research). C. Dive is funded by CRUK Core funding to Manchester Institute (C5757/A27412) and is supported by the CRUK Manchester Centre Award (C5759/A25254), and by the NIHR Manchester Biomedical Research Centre. C. Zhou is funded by the CRUK Manchester Centre Award (C5759/A25254), J. Stevenson and P. Fitzpatrick are funded by the CRUK Accelerator Award (29374). This research was funded in part, by the Wellcome Trust [205228/Z/16/Z]. LT is also supported by the National Institute for Health Research Health Protection Research Unit (HPRU) in Emerging and Zoonotic Infections (NIHR200907) at University of Liverpool in partnership with Public Health England (PHE), in collaboration with Liverpool School of Tropical Medicine and the University of Oxford. LT is based at University of Liverpool. The views expressed are those of the author(s) and not necessarily those of the NHS, the NIHR, the Department of Health or Public Health England. Funding for COVID-19 work has been provided by The Christie Charitable fund (1049751). 
medRxiv preprint doi: https://doi.org/10.1101/2020.11.30.20239095; this version posted December 3, 2020. The copyright holder for this preprint (which was not certified by peer review) is the author/funder, who has granted medRxiv a license to display the preprint in perpetuity. It is made available under a CC-BY-NC-ND 4.0 International license.

Acknowledgements: Clare Griffin and Alison Backen for their support in the project. Digital ECMT team for insights into data analysis. Manchester and Liverpool ECMC.

Conflicts of interest: R Lee speaker fees BMS and Astrazeneca, M Rowe honoraria from Astellas Pharma, speaker fees MSD and Servier. C. Wilson consultancy and speaker fees Pfizer, Amgen, Novartis, A Armstrong conference fee Merck, spouse shares in Astrazeneca. T Robinson financial support to attend educational workshops from Amgen and DaiichiSankyo. C Dive, outside of this scope of work, has received research funding from AstraZeneca, Astex Pharmaceuticals, Bioven, Amgen, Carrick Therapeutics, Merck AG, Taiho Oncology, Clearbridge Biomedics, Angle PLC, Menarini Diagnostics, GSK, Bayer, Boehringer Ingelheim, Roche, BMS, Novartis, Celgene, Thermofisher. C Dive is on advisory boards for, and has received consultancy fees/honoraria from, AstraZeneca, Biocartis and Merck KGaA. 


\begin{abstract}
Background: Cancer patients are at increased risk of severe COVID-19. As COVID-19 presentation and outcomes are heterogeneous in cancer patients, decision-making tools for hospital admission, severity prediction and increased monitoring for early intervention are critical.
\end{abstract}

Objective: To identify features of COVID-19 in cancer patients predicting severe disease and build a decision-support online tool; COVID-19 Risk in Oncology Evaluation Tool (CORONET)

Method: Data was obtained for consecutive patients with active cancer with laboratory confirmed COVID-19 presenting in 12 hospitals throughout the United Kingdom (UK). Univariable logistic regression was performed on pre-specified features to assess their association with admission ( $\geq 24$ hours inpatient), oxygen requirement and death. Multivariable logistic regression and random forest models (RFM) were compared with patients randomly split into training and validation sets. Cost function determined cut-offs were defined for admission/death using RFM. Performance was assessed by sensitivity, specificity and Brier scores (BS). The CORONET model was then assessed in the entire cohort to build the online CORONET tool.

Results: Training and validation sets comprised 234 and 66 patients respectively with median age 69 (range 19-93), 54\% males, 46\% females, 71\% vs 29\% had solid and haematological cancers. The RFM, selected for further development, demonstrated superior performance over logistic regression with AUROC predicting admission ( 0.85 vs. 0.78 ) and death $(0.76$ vs. 0.72 ). C-reactive protein was the most important feature predicting COVID19 severity. CORONET cut-offs for admission and mortality of 1.05 and 1.8 were established. In the training set, admission prediction sensitivity and specificity were $94.5 \%$ and $44.3 \%$ with BS 0.118; mortality sensitivity and specificity were $78.5 \%$ and $57.2 \%$ with BS 0.364 . In the validation set, admission sensitivity and specificity were $90.7 \%$ and $42.9 \%$ with BS 0.148 ; mortality sensitivity and specificity were $92.3 \%$ and $45.8 \%$ with BS 0.442 . In the entire cohort, the CORONET decision support tool recommended admission of $99 \%$ of patients requiring oxygen and of $99 \%$ of patients who died.

Conclusions and Relevance: CORONET, a decision support tool validated in hospitals throughout the UK showed promise in aiding decisions regarding admission and predicting COVID-19 severity in patients with cancer presenting to hospital. Future work will validate and refine the tool in further datasets. 
medRxiv preprint doi: https://doi.org/10.1101/2020.11.30.20239095; this version posted December 3, 2020. The copyright holder for this preprint (which was not certified by peer review) is the author/funder, who has granted medRxiv a license to display the preprint in perpetuity.

\author{
It is made available under a CC-BY-NC-ND 4.0 International license.
}




\section{Introduction}

The SARS-CoV-2 virus has infected over 30 million people to date, resulting in over a million deaths worldwide (1). A diverse spectrum of clinicopathological syndromes have been reported, ranging from asymptomatic cases to multi-organ failure and death (2). Standard medical care involves supportive therapies in those requiring hospital admission, with reduced mortality reported with dexamethasone in patients requiring oxygen or mechanical ventilation (3). Patients with milder symptoms have been safely managed as outpatients. Patients with cancer are at significantly increased risk of severe complications from COVID19 including need for invasive ventilation and death $(2,4)$. In two large case series and a meta-analysis of 18,650 patients, fatality rates of $10-30 \%$ have been observed in patients with cancer (5-7). Older age, male sex, Eastern Cooperative Oncology Group performance status (PS), smoking status, active cancer, haematological cancer and presence of other comorbidities such as hypertension have been shown to be significantly associated with mortality from COVID-19 (5-11).

Identifying oncology patients at risk of deterioration necessitating inpatient admission presents a unique challenge for healthcare professionals due to heterogeneity of clinical manifestations of COVID-19 and difficulty in distinguishing them from the complications of cancer and its therapy. In addition, to reduce burden on the health system and risk of nosocomial/hospital staff infection, it is important to admit only those patients who are likely to require additional supportive measures. A living review of risk prediction models has reported that current models are at high risk of bias and are poorly reported (12). More recently, the ISARIC 4 C model has been developed using data from 57,824 patients in the United Kingdom (UK) to develop a score based on clinical/laboratory parameters (13). Although patients with a history of cancer were included in model development, it is unclear how well it performs in patients with active cancer.

We investigated clinical, haematological, and biochemical features in patients with active cancer presenting to hospital with COVID-19. Crucially, we wanted to create a pragmatic tool that can be readily applied in hospitals with parameters easily obtained through clinical history, examination and laboratory assessment. We developed a model, which aimed to predict whether cancer patients could be discharged safely without serious sequelae vs. severe disease requiring oxygen $\left(\mathrm{O}_{2}\right)$ or death. Using this model we built an online tool; 
CORONET (COvid Risk Oncology Evaluation Tool) to support healthcare professionals in decisions regarding admission and to provide information as to the likely severity of illness. This is the first step of an iterative process whereby the tool will have ongoing refinement as more data and knowledge regarding COVID-19 and its treatment in cancer patients are obtained.

\section{Methods}

Study settings

Research Ethics Committee approval (reference 20/WA/0269) was granted to use a database of cancer patients presenting with COVID-19 (14) to establish the decision support tool and for follow-on data collection to be obtained prospectively, specifically for the CORONET project (see Supp methods).

\section{Data collection}

Active cancer was defined as solid or haematological cancer diagnosed in the last 6 months or undergoing treatment for cancer or recurrent or metastatic cancer or haematological cancer not in complete remission for $\geq 6$ months. Asymptomatic patients who were screened and found positive as part of routine testing for surgical procedures were not included due to lack of data. Patients had to have a laboratory confirmed SARS-CoV-2 infection (which for the majority was PCR-based).

\section{Selection of clinical, haematological, and biochemical features}

Clinical, haematological and biochemical data were collected based on a pre-specified feature list including demographic/physiological features, oncology specific factors associated with poor cancer outcome such as performance status, literature review of features of COVID-19 severity and our previous work examining patients with cancer and COVID-19 longitudinally (14). Parameters were taken at presentation to hospital with symptoms of COVID-19, which was later laboratory confirmed or if already an inpatient, taken as close to/at the time of positive COVID-19 result (see Supp. methods for definitions of parameters).

\section{Patient outcomes}

Admission ( $\geq 24$ hours inpatient), $\mathrm{O}_{2}$ requirement and death were used as measures of infection severity. If outcomes were missing, the following assumptions were made: every patient that died due to COVID-19 also received $\mathrm{O}_{2}$ during hospital stay $4 \%, 11$ pts missing 
$\left.\mathrm{O}_{2}\right)$, patients discharged within 24 hours did not receive $\mathrm{O}_{2}\left(<1 \%, 2\right.$ pts missing $\left.\mathrm{O}_{2}\right)$, patients that were inpatients for non-COVID reasons were also considered to be admitted $<<1 \%, 2$ pts missing $\mathrm{O}_{2}$ ), patients that died due to non-COVID reasons (deemed by clinician as asymptomatic of COVID-19 and dying of cancer) did not receive $\mathrm{O}_{2}$, patients admitted into ITU also received $\mathrm{O}_{2}\left(<1 \%, 2\right.$ pts missing $\left.\mathrm{O}_{2}\right)$.

Study design

Transparent reporting of multivariable prediction models for individual prognosis or diagnosis (TRIPOD) guidelines have been used to report findings (15). Results from published data suggested that for parameters significantly associated with worse outcome in cancer patients with COVID-19, a sample size of 57 patients would provide a power of $90 \%$, at a significance level of 0.05 ; for albumin minimum sample size $=28$, CRP minimum sample size= 25 , neutrophils minimum sample size $=57$. In this study all statistical tests and modelling were carried out using R (ver 3.6.2) and Python (ver 3.7) (16,17).

\section{Model development}

Model development workflow (Fig 1.) consisted of three stages: firstly an exploratory Pearson's correlation analysis was performed to explore relationships between haematological and biochemical features. Univariable logistic regression analysis was carried out with each clinical/haematological/biochemical feature as an independent variable and each COVID-19 outcome as the dependent. This stage took place prior to model derivation, with the aim to screen for possible significant predictors for COVID-19 outcomes and explore the possible biology behind them. Features with p-values smaller than 0.1 were selected to go into the next analysis stage, except those with significant data missing (>50\%). For patients with less than 2 missing features, missing values (haematological/biochemical only) were then imputed using multiple imputation.

Secondly, patients were randomly split into training ( $80 \%, 9$ hospitals, 219 patients) and validation cohorts ( $20 \%, 3$ hospitals, 60 patients) according to treating hospitals. Two different modelling approaches were applied: a multivariable logistic regression approach, selected due to model interpretability and its wide use in COVID-19 models currently available (13); plus a random forest approach (18), selected because of its superior theoretical accuracy as a machine learning method while still maintaining good interpretability compared to more sophisticated machine learning approaches. 
The two models were developed in parallel and were compared in terms of both their statistical performance and clinical explainability. The final feature list for logistic regression was achieved using a backward stepwise method. Features with high correlation or with high biological relevance were manually inspected. Feature importance in the random forest model was evaluated using impurity (18). Model performance was evaluated by the area under receiver operating characteristic curve (AUROC) using 10-fold cross validation.

Finally, we identified optimal cut-offs to address key clinical questions namely necessity for admission due to likely severe COVID-19 and prediction of death. A cost function approach was adopted to address the imbalance of COVID-19 outcomes particularly surrounding admission where we observed a smaller number of patients being discharged (13\%) vs. admitted ( $87 \%$ Table 1). The performance of the derived cut-offs were assessed by their sensitivity, specificity and Brier scores (19). In parallel we compared mortality prediction with the ISARIC 4C model and examined its utility in a cancer population (13).

\section{Model validation and CORONET development}

The derived model and suggested cut-offs were validated using the validation patient cohort, with sensitivity, specificity and Brier score to assess performance and calibration. Finally we updated and evaluated the model in the entire cohort of patients in order to provide the full data set to inform the CORONET online decision support tool.

\section{Results}

\section{Clinical characteristics}

Data collection was conducted between March-June 2020 from 12 participating hospitals, (mixture of local district general and tertiary centres, Supp. table 1.) throughout the United Kingdom (UK). Data for consecutive patients were obtained, with minimum 30 days follow up. Clinical features of all the patients are shown in Table 1. For the entire cohort, the median age was 69 , range $19-93$, with $54 \%$ males and $46 \%$ females and $71 \%$ having been diagnosed with a solid tumour whilst $29 \%$ had a haematological cancer. At the time of data cut-off, we grouped patients presenting with SARS-CoV-2 according to whether they had experienced 3 main outcomes associated with severity of COVID-19; admission to hospital ( $\geq 24$ hours, $87 \%$ of patients), $\mathrm{O}_{2}$ (57\% of patients) and death (29\%). Very few patients (2\%) were admitted to intensive care (ITU) therefore it was not used as an outcome measure for analysis. 
Haematological and biochemical data are summarised in Supp. Table 2. Correlation between several biochemical and haematological measurements was low (median $r=0.13$, Supp. Fig. 1.), with maximum correlation observed between platelets and neutrophils (maximum $r=0.49$ ). We first performed univariable logistic regression analysis to assess the association between COVID-19 outcomes (admission/ $\mathrm{O}_{2} /$ death) and each clinical, biochemical and haematological variable (Table 2). A patient was significantly more likely to have severe COVID-19 outcomes $\left(\mathrm{O}_{2}\right.$ and death) if they were older, male, had cardiovascular disease, high total number of comorbidities, haematological cancer advanced stage cancer (solid tumours examined only), poor performance status, high CRP, low albumin, high neutrophils, low oxygen saturation, high neutrophil/lymphocyte ratio (NLR), high LDH and high National Early Warning Score 2 (NEWS2 (20)) score (Table 2). Conversely, hospital admission was associated with a simpler set of variables: age, total number of comorbidities, CRP, albumin, SATs, LDH and NEWS2 score (Table 2). The discrepancy between significant features informing different outcomes was confirmed in multivariable logistic regression analysis (Table 2). For example, patients with haematological cancer had significantly higher risk of death ( $p=0.002$ ) according to multivariate analysis, but it was not associated with increased hospital admission $(p=0.327)$.

\section{Modelling COVID-19 severity using combined outcomes}

The discrepancy between factors significantly associated with different COVID-19 outcomes (admission vs. $\mathrm{O}_{2}$ and death) indicated that a decision on hospital admission needed to be improved by considering the risk of requiring $\mathrm{O}_{2}$ and death. Thus, a combined COVID-19 outcome was generated to represent severity, with multivariable logistic regression and random forest models subsequently developed using features significant in Table 2.

Performance of logistic regression and random forest models were evaluated by using them as a classifier to predict patient admission and death (Fig. 2). The random forest demonstrated superior performance with an AUC of ROC higher than that of logistic regression in both prediction of admission ( 0.85 vs. 0.78 ) and death ( 0.76 vs. 0.72$)$ therefore was selected for further development. The importance of features involved in the random forest model are shown in Supp Fig 2, in which CRP was considered the most important feature to predict COVID-19 severity.

Cut-offs for predicting hospital admission and patient mortality were determined using a cost function approach to compensate for data imbalance (Supp Fig 3). The cut-off for admission was determined to be 1.05 , while that for mortality being 1.8. At these 
thresholds, the model achieved a sensitivity of $78.5 \%$, a specificity of $57.2 \%$, and a Brier score of 0.364 in predicting patient mortality. Critically, for prediction of the need for admission it achieved a sensitivity of $94.5 \%$, a specificity of $44.3 \%$, and a Brier score of 0.118 . Performance of the model in the validation cohort

Model performance was evaluated using the validation dataset (Supp. Table 3). The model achieved a consistent performance in admission with a sensitivity of $90.7 \%$, a specificity of $42.9 \%$ and a Brier score of 0.148 . For mortality, the model achieved a sensitivity of $92.30 \%$, a specificity of $45.8 \%$ and a Brier score of 0.442 .

\section{Comparison with ISARIC 4C score}

Next, we identified a subset of 128 patients (named CORONET-4C), which had complete data available for parameters in both CORONET and ISARIC 4C mortality (4C (13)) models in order to compare them. In this subset, the AUROC for mortality for $4 \mathrm{C}$ was 0.81 and CORONET 0.74 . Of note, $4 \mathrm{C}$ mortality scores in the CORONET-4C cohort were lower than the original $4 C$ cohort, which was determined using predominantly non-cancer populations (Supp Fig. 4A). In addition, cancer patients were consistently more likely to die at lower values of the $4 \mathrm{C}$ score (Supp Fig. $4 \mathrm{~B}$ ). For example at a $4 \mathrm{C}$ score of $\leq 6$, mortality was $4.5 \%$ in the original $4 \mathrm{C}$ validation cohort whereas in CORONET-4C it was $8.3 \%$ (Supp. Table 4). Critically, CORONET recommended admission of $100 \%$ of those patients who died and had $4 C$ score $\leq 9$, as well as $100 \%$ of patients with $4 C \geq 9$. CORONET was trained on requirement for admission based on oxygen and death, which differed from the $4 \mathrm{C}$ model, which focused on risk of mortality. We therefore compared the $4 \mathrm{C}$ score rule in mortality threshold $(\geq 9)$ and CORONET admission/severity thresholds (Supp. Figure 5). This revealed that the CORONET threshold safely admitted those patients who had required oxygen or died.

\section{Development of CORONET decision support tool}

We applied the random forest model to patients in the entire cohort $(n=279)$ and based on this developed the CORONET online platform. To demonstrate calibration of the updated CORONET model, its prediction of patient admission, $\mathrm{O}_{2}$ and mortality were plotted by hospital (Fig. 3). Critically, the CORONET score recommended admission for $99 \%$ of patients requiring $\mathrm{O}_{2}$ and $99 \%$ patients who died in the entire cohort, supporting its safety as a decision support tool. 


\section{Discussion}

Many studies have provided important data regarding risks of COVID-19 in the cancer population, which have helped to inform oncologists and patients in discussions regarding shielding, treatments and admissions with COVID-19 $(5,6,8,10,11)$. We focused on developing a cancer-specific model of risk and decision support tool, which could aid the oncology and acute-care communities in discussions and decisions at the point of admission assessment of patients with symptoms of COVID-19.

In this cohort, the random forest model had the best performance with an AUROC of 0.85 for admission and 0.76 for death, which validated in different hospitals. Critically, in the entire cohort it recommended admission for $99 \%$ of patients who went on to require oxygen and $99 \%$ of the patients who died. In establishing our cut-offs, we prioritised achieving high sensitivity, which resulted in decreased specificity, but increased safety of the decision support tool. Modelling individual outcomes alone (e.g. death), may result in data overfitting and does not reflect overall disease severity, therefore we chose to model a combined COVID-19 outcome. This may result in reduced accuracy on classification for a specific outcome, but improved generality to reflect COVID-19 severity, which was important for decision-making regarding hospital admission. We were also less stringent regarding those patients who were admitted but survived and did not receive oxygen, as these patients could potentially be managed at home. Patients may have been admitted due to oncological problems rather than COVID-19, therefore it is important to stress that the decision support tool is specific to COVID-19 rather than cancer-related decisions to admit.

Laboratory features such as CRP and clinical features such as age and haematological cancer have been shown to be independent risk factors by a number of groups $(5,8,10,11)$. In other cohorts male sex and performance status have been identified as important independent negative prognostic factors; however these variables did not add to the predictive capability of our model $(5,10)$. Intriguingly, haematological cancer and solid tumour stage were not as important as features such as CRP suggesting the COVID-19 induced inflammatory state is most critical in predicting severity. But, as patients with higher stage/haematological cancer are significantly more likely to develop severe COVID-19, these features are still useful for admission decisions. In addition, NEWS2 is commonly used within the UK to identify patients who are at risk of severe illness (20). Although NEWS2 has its own limitations and has been criticised especially in applicability to primary care (21), our validation of it as an important feature of severity in patients with cancer and COVID-19 suggests that it is helpful in the assessment of patients at least in the hospital setting. 
We compared our model to the ISARIC 4C mortality risk score, created based on data from over 57,000 patients (13). Although a small cohort, it is important to note that our analysis of cancer patients using $4 \mathrm{C}$ showed that they were at higher risk of mortality with a lower 4C-score compared to the whole ISARIC population, which was mainly composed of patients without cancer. Thus, lower thresholds should be considered when using the $4 \mathrm{C}$ score in assessing patients with cancer. The $4 \mathrm{C}$ score had a better AUC for mortality compared to CORONET, which was likely due to our model training being focussed on admission of patients who were not only likely to die but also to require oxygen. In support of this, our model performed better in admission of patients requiring oxygen as a measure of COVID-19 severity. In addition, all those patients predicted by $4 \mathrm{C}$ to be at risk of mortality were admitted using our CORONET model, which is an important validation of its safety. Further comparisons in larger cohorts of patients are needed to better understand the benefits/limitations of each model in cancer patients.

There were several limitations in our model development. Firstly, the cohort is relatively small, however, according to the study design, it had sufficient power to detect significant differences in outcomes and validated across multiple hospitals. Through focusing on patients presenting to hospital, we selected a population biased towards more severe COVID-19. In addition, although we managed missing data through imputation and some assumptions (small numbers), we did not have sufficient data on features shown to be important in other cohorts such as ethnicity and LDH to incorporate into the analysis. These aspects will be addressed in future work validating the model further in international cohorts and prospective collection of additional parameters/data as more patients are admitted.

The majority of healthcare professionals have access to the internet and hospital results are increasingly accessed online. Consequently and in parallel, we have created a companion online decision tool (CORONET; COVID-19 risk in Oncology Evaluation Tool available at https://coronet.manchester.ac.uk/), which enables our model to be easily used. However, we recognise that for those working in resource poor settings this may provide a barrier to use and can provide further assistance if required. The tool is planned to provide prognostic information regarding the outcome of the patient in addition to assessment of how features of the individual define the outcome reported by the tool. In this way, we aim to support greater recognition of features that are associated with more severe outcomes for patients with cancer and COVID-19. 
Critically, we view the creation and ongoing development of the decision support tool as an iterative process. This first version is a foundation upon which to improve as more data are obtained and more decision support features are created and validated in different hospitals. Using CORONET, healthcare professionals can be supported in their management of cancer patients with COVID-19. It aids discussions with patients and their families regarding likely prognosis, which is crucial to ensuring they are fully informed. It will support decisions regarding safe early discharge of patients, reducing hospital stay with beneficial impacts to emergency services, cost-savings and reducing risk of infecting staff/other patients. Furthermore, it will provide information, which can be used to identify those who might benefit from more intensive monitoring and to make early decisions regarding escalation to intensive care. In future, it may be used to identify patients at risk of severe COVID-19 who may have greatest benefit from interventions. Individualized management of COVID-19 presentations in cancer patients is crucial to providing sustainable emergency oncology care during the COVID-19 pandemic and beyond.

\section{Data availability}

Code for the tool is available at Github (https://github.com/oskwys/CORONET). Raw data is available upon request to corresponding author, however may not include all details due to information governance regulations. 


\section{References}

1. Dong E, Du H, Gardner L. An interactive web-based dashboard to track COVID-19 in real time [Internet]. Vol. 20, The Lancet Infectious Diseases. Lancet Publishing Group; 2020 [cited 2020 Oct 3]. p. 533-4. Available from: https://www.who.int/china/news/

2. Guan W, Ni Z, Hu Y, Liang W, Ou C, He J, et al. Clinical Characteristics of Coronavirus Disease 2019 in China. N Engl J Med [Internet]. 2020 Apr 30 [cited 2020 May 12];382(18):1708-20. Available from: http://www.nejm.org/doi/10.1056/NEJMoa2002032

3. Horby P, Lim WS, Emberson J, Mafham M, Bell J, Linsell L, et al. Dexamethasone for COVID-19-Preliminary Report Effect of Dexamethasone in Hospitalized Patients with COVID-19-Preliminary Report RECOVERY Collaborative Group* [Internet]. medRxiv. Cold Spring Harbor Laboratory Press; 2020 Jun [cited 2020 Jul 2]. Available from: https://www.medrxiv.org/content/10.1101/2020.06.22.20137273v1

4. Liang W, Guan W, Chen R, Wang W, Li J, Xu K, et al. Cancer patients in SARS-CoV-2 infection: a nationwide analysis in China. Vol. 21, The Lancet Oncology. Lancet Publishing Group; 2020. p. 335-7.

5. Collaborative TO, Williamson E, Walker AJ, Bhaskaran KJ, Bacon S, Bates C, et al. OpenSAFELY: factors associated with COVID-19-related hospital death in the linked electronic health records of 17 million adult NHS patients. medRxiv. 2020 May 7;2020.05.06.20092999.

6. Lee LYW, Cazier JB, Starkey T, Turnbull CD, Kerr R, Middleton G. COVID-19 mortality in patients with cancer on chemotherapy or other anticancer treatments: a prospective cohort study. Lancet [Internet]. 2020 May [cited 2020 May 31];0(0). Available from: https://linkinghub.elsevier.com/retrieve/pii/S0140673620311739

7. Kuderer NM, Choueiri TK, Shah DP, Shyr Y, Rubinstein SM, Rivera DR, et al. Clinical impact of COVID-19 on patients with cancer (CCC19): a cohort study. Lancet [Internet]. 2020 May [cited 2020 May 31];0(0). Available from: https://linkinghub.elsevier.com/retrieve/pii/S0140673620311879

8. Saini KS, Tagliamento M, Lambertini M, McNally R, Romano M, Leone M, et al. Mortality in patients with cancer and coronavirus disease 2019: A systematic review and pooled analysis of 52 studies. Eur J Cancer. 2020 Nov 1;139:43-50.

9. Albiges L, Foulon S, Bayle A, Gachot B, Pommeret F, Willekens C, et al. Determinants of the outcomes of patients with cancer infected with SARS-CoV-2: results from the Gustave Roussy cohort. Nat Cancer [Internet]. 2020 Sep 22 [cited 2020 Oct 3];1-11. Available from: http://www.nature.com/articles/s43018-020-00120-5

10. Lee LYW, Cazier JB, Starkey T, Briggs SEW, Arnold R, Bisht V, et al. COVID-19 prevalence and mortality in patients with cancer and the effect of primary tumour subtype and patient demographics: a prospective cohort study. Lancet Oncol [Internet]. 2020 Oct 1 [cited 2020 Oct 3];21(10):1309-25. Available from: www.thelancet.com/oncology

11. Wu C, Chen X, Cai Y, Xia J, Zhou X, Xu S, et al. Risk Factors Associated With Acute Respiratory Distress Syndrome and Death in Patients With Coronavirus Disease 2019 Pneumonia in Wuhan, China. JAMA Intern Med [Internet]. 2020 Mar 13 [cited 2020 May 12]; Available from:

https://jamanetwork.com/journals/jamainternalmedicine/fullarticle/2763184 
12. Williamson EJ, Walker AJ, Bhaskaran K, Bacon S, Bates C, Morton CE, et al. OpenSAFELY: factors associated with COVID-19 death in 17 million patients. Nature [Internet]. 2020 Jul 8 [cited 2020 Jul 8];1-11. Available from:

http://www.nature.com/articles/s41586-020-2521-4

13. Wynants L, Van Calster B, Bonten MMJ, Collins GS, Debray TPA, De Vos M, et al. Prediction models for diagnosis and prognosis of covid-19 infection: Systematic review and critical appraisal. BMJ. 2020 Apr 7;369.

14. Henry BM, De Oliveira MHS, Benoit S, Plebani M, Lippi G. Hematologic, biochemical and immune biomarker abnormalities associated with severe illness and mortality in coronavirus disease 2019 (COVID-19): A meta-analysis [Internet]. Vol. 58, Clinical Chemistry and Laboratory Medicine. De Gruyter; 2020 [cited 2020 Oct 4]. p. 1021-8. Available from: https://pubmed.ncbi.nlm.nih.gov/32286245/

15. Wynants L, Van Calster B, Collins GS, Riley RD, Heinze G, Schuit E, et al. Prediction models for diagnosis and prognosis of covid-19: Systematic review and critical appraisal. BMJ [Internet]. 2020 Apr 7 [cited 2020 Oct 4];369:18. Available from: https://www.bmj.com/content/369/bmj.m1328

16. Knight SR, Ho A, Pius R, Buchan I, Carson G, Drake TM, et al. Risk stratification of patients admitted to hospital with covid-19 using the ISARIC WHO Clinical Characterisation Protocol: Development and validation of the 4C Mortality Score. BMJ [Internet]. 2020 Sep 9 [cited 2020 Oct 4];370:22. Available from: http://dx.doi.org/10.1136/bmj.m3339

17. Health Research Auth ority. Guidance for using patient data - Health Research Authority [Internet]. 2020 [cited 2020 Aug 23]. Available from: https://www.hra.nhs.uk/covid-19-research/guidance-using-patient-data/

18. Lee RJ, Wysocki O, Bhogal T. Longitudinal characterisation of haematological and biochemical parameters in cancer patients prior to and during COVID-19 reveals features associated with outcome. ESMO Open. 2020;

19. Pinato DJ, Zambelli A, Aguilar-Company J, Bower M, Sng CCT, Salazar R, et al. Clinical Portrait of the SARS-CoV-2 Epidemic in European Patients with Cancer. Cancer Discov [Internet]. 2020 Oct 1 [cited 2020 Nov 1];10(10):1465-74. Available from: http://cancerdiscovery.aacrjournals.org/

20. Mehta V, Goel S, Kabarriti R, Cole D, Goldfinger M, Acuna-Villaorduna A, et al. Case Fatality Rate of Cancer Patients with COVID-19 in a New York Hospital System. Cancer Discov [Internet]. 2020 May 1 [cited 2020 Jul 12];10(7):935-76. Available from: http://cancerdiscovery.aacrjournals.org/

21. National Early Warning Score (NEWS) 2 | RCP London [Internet]. [cited 2020 Oct 4]. Available from: https://www.rcplondon.ac.uk/projects/outputs/national-earlywarning-score-news-2

22. NEWS (or NEWS2) score when assessing possible COVID-19 patients in primary care? - CEBM [Internet]. [cited 2020 Oct 4]. Available from: https://www.cebm.net/covid19/should-we-use-the-news-or-news2-score-when-assessing-patients-with-possiblecovid-19-in-primary-care/ 


\section{Figure legends}

Figure 1. Modelling workflow.

Model training and validation workflow. $A U C=$ area under the curve, $\mathrm{ROC}=$ receiver operating curve, $4 \mathrm{C}=$ ISARIC $4 \mathrm{C}$

Figure 2. Performance of the random forest model and the logistic regression model in predicting patient admission and death

Area under receiving operator curve for logistic regression model and random forest model in predicting admission and mortality in patients presenting to hospital with COVID-19.

Figure 3. CORONET score and outcome in cancer patients presenting with COVID-19 to each hospital in the cohort

CORONET score calculated using Leave-One Out Cross Validation for 279 patients with cancer, stratified by hospital. 
Tables

Table 1. Summary of patients' clinical characteristics

\begin{tabular}{|c|c|c|}
\hline Names & Description & Number (\%) \\
\hline \multirow[t]{6}{*}{ Age } & $<40$ & $15(5 \%)$ \\
\hline & $40-49$ & $12(4 \%)$ \\
\hline & $50-59$ & $40(13 \%)$ \\
\hline & $60-69$ & $79(26 \%)$ \\
\hline & $70-79$ & $101(34 \%)$ \\
\hline & $>=80$ & $47(16 \%)$ \\
\hline \multirow[t]{2}{*}{ Sex } & Male & $162(54 \%)$ \\
\hline & Female & $138(46 \%)$ \\
\hline \multirow[t]{2}{*}{ Cancer type } & Haematological cancer & $86(29 \%)$ \\
\hline & Solid tumour & $214(71 \%)$ \\
\hline \multirow{3}{*}{$\begin{array}{l}\text { Cancer stage (solid } \\
\text { tumours only) }\end{array}$} & 1 or 2 & $46(15 \%)$ \\
\hline & 3 & $49(16 \%)$ \\
\hline & 4 & $108(36 \%)$ \\
\hline \multirow{4}{*}{$\begin{array}{l}\text { Therapy within } 4 \text { weeks } \\
\text { of infection* }\end{array}$} & Chemotherapy & $116(39 \%)$ \\
\hline & Immunotherapy & $14(5 \%)$ \\
\hline & Targeted therapy & $48(16 \%)$ \\
\hline & Radiotherapy & $25(8 \%)$ \\
\hline \multirow[t]{2}{*}{ Chest X-ray } & Consistent with pneumonia & $90(30 \%)$ \\
\hline & Not consistent with pneumonia & $76(25 \%)$ \\
\hline \multirow[t]{2}{*}{ Treatment intent } & Early/radical & $92(31 \%)$ \\
\hline & Advanced/palliative & $181(60 \%)$ \\
\hline \multirow{5}{*}{$\begin{array}{l}\text { Specific co-morbidities } \\
\text { of interest }\end{array}$} & Chronic obstructive pulmonary disease & $38(13 \%)$ \\
\hline & Diabetes & $58(19 \%)$ \\
\hline & Chronic kidney disease & $72(24 \%)$ \\
\hline & Cardiovascular disease & $67(22 \%)$ \\
\hline & Hypertension & $93(31 \%)$ \\
\hline NEWS2 score & $0-1$ & $127(42 \%)$ \\
\hline
\end{tabular}


medRxiv preprint doi: https://doi.org/10.1101/2020.11.30.20239095; this version posted December 3, 2020. The copyright holder for this preprint (which was not certified by peer review) is the author/funder, who has granted medRxiv a license to display the preprint in perpetuity. It is made available under a CC-BY-NC-ND 4.0 International license.

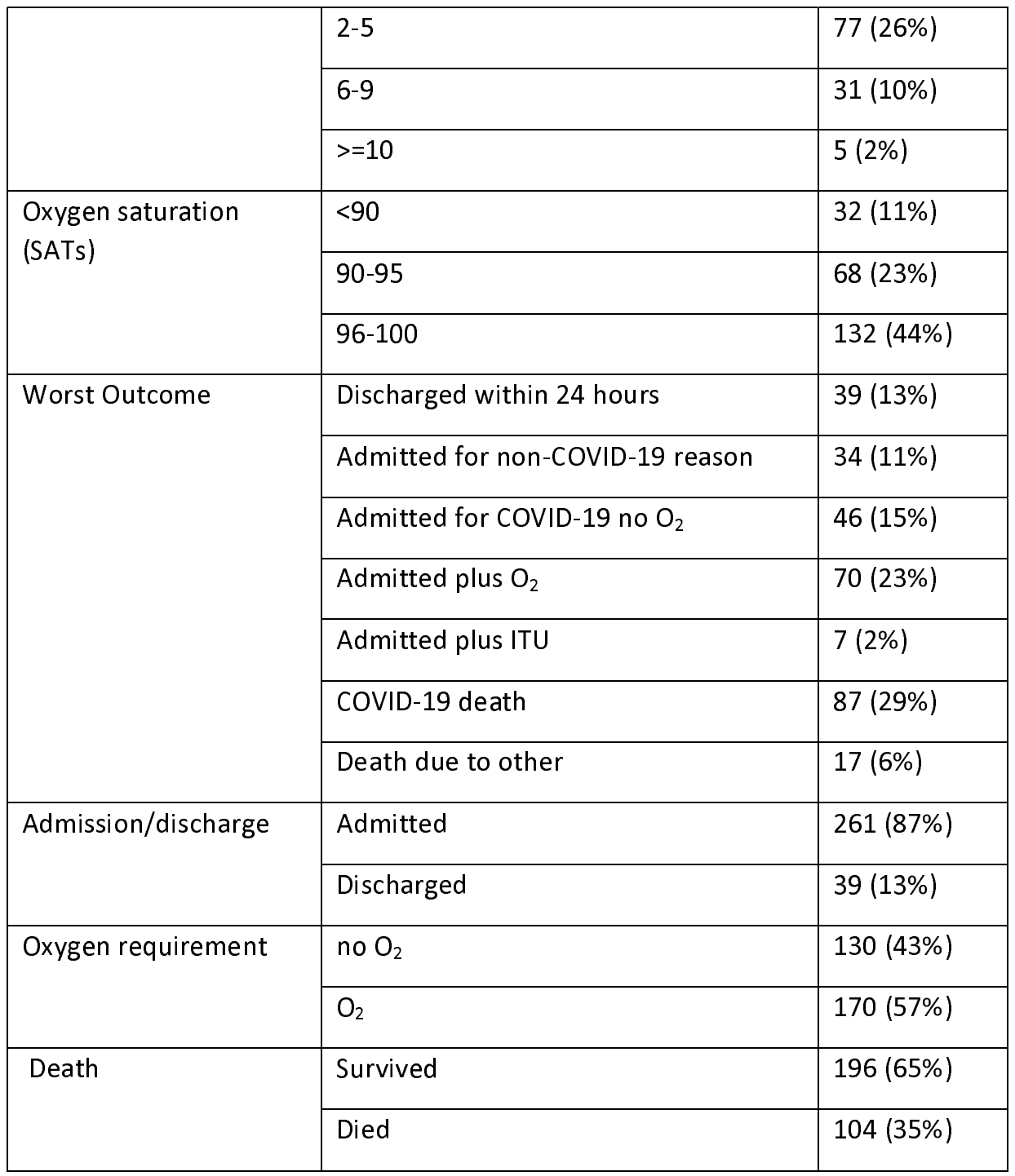

* Can have more than one therapy 


\section{Table 2. Association between COVID-19 outcomes and patient clinical/haematological/biochemical characteristics}

\begin{tabular}{|c|c|c|c|c|c|c|c|}
\hline & & \multicolumn{3}{|c|}{ Univariable association analysis } & \multicolumn{3}{|c|}{ Multivariable association analysis } \\
\hline & & Admission & Required Oxygen & Death & Admission & Required Oxygen & Death \\
\hline Variable Name & Description & $\begin{array}{l}\text { P-values (odds } \\
\text { ratio) }\end{array}$ & $\begin{array}{l}\text { P-values (odds } \\
\text { ratio) }\end{array}$ & $\begin{array}{l}\text { P-values (odds } \\
\text { ratio) }\end{array}$ & $\begin{array}{l}\text { P-values (odds } \\
\text { ratio) }\end{array}$ & $\begin{array}{l}\text { P-values (odds } \\
\text { ratio) }\end{array}$ & $\begin{array}{l}\text { P-values (odds } \\
\text { ratio) }\end{array}$ \\
\hline Age & Continuous & $1.32 \mathrm{E}-4(1.044)$ & $1.44 \mathrm{E}-5(1.043)$ & $6.63 \mathrm{E}-6(1.060)$ & $0.083(1.023)$ & NS & $0.002(1.051)$ \\
\hline Sex & Male vs. female & $0.984(1.007)$ & $0.013(1.793)$ & $0.032(1.750)$ & NS & NS & NS \\
\hline \multirow[t]{6}{*}{ Comorbidity } & COPD yes vs. no & $0.618(1.322)$ & $0.282(1.478)$ & $0.500(1.283)$ & NS & NS & NS \\
\hline & HTN yes vs. no & $0.950(1.024)$ & $0.402(1.239)$ & $0.039(1.731)$ & NS & NS & NS \\
\hline & Cardiovascular yes vs.no & $0.122(2.140)$ & $0.001(2.628)$ & $0.002(2.418)$ & NS & NS & NS \\
\hline & Diabetes yes vs. no & $0.263(1.750)$ & $0.054(1.818)$ & $0.359(1.331)$ & NS & NS & NS \\
\hline & $\begin{array}{l}\text { Chronic kidney disease yes vs. } \\
\text { no }\end{array}$ & $0.303(0.678)$ & $0.694(1.115)$ & $0.608(1.163)$ & NS & NS & NS \\
\hline & Total number of comorbidities & $0.039(1.375)$ & $1.58 \mathrm{E}-4(1.438)$ & $0.006(1.255)$ & NS & $0.005(1.048)$ & NS \\
\hline Haematological Cancer & Yes vs. no & $0.946(1.026)$ & $0.256(1.347)$ & $0.001(2.413)$ & NS & $0.039(2.118)$ & $0.004(2.683)$ \\
\hline \multirow[t]{2}{*}{ Solid Tumour Stage } & 3 vs. $1 / 2$ & $0.681(1.260)$ & $0.493(0.756)$ & $0.133(0.411)$ & NS & $0.056(0.384)$ & NS \\
\hline & 4 vs. $1 / 2$ & $0.338(1.607)$ & $0.079(1.867)$ & $0.257(1.600)$ & NS & $0.349(0.833)$ & NS \\
\hline Treatment within 4 & Chemotherapy yes vs. no & $0.351(0.725)$ & $0.031(0.596)$ & $0.874(0.959)$ & NS & NS & NS \\
\hline
\end{tabular}


COVID-19 risk prediction in cancer patients

\begin{tabular}{|c|c|c|c|c|c|c|c|}
\hline \multirow[t]{3}{*}{ weeks } & Radiotherapy yes vs. no & $0.653(0.772)$ & $0.809(1.108)$ & $0.861(0.922)$ & NS & NS & NS \\
\hline & Targeted therapy yes vs. no & $0.769(0.846)$ & $0.297(0.656)$ & $0.684(0.830)$ & NS & NS & NS \\
\hline & Immune therapy yes vs. no & $0.884(0.892$ & $0.293(1.887)$ & $0.509(0.645)$ & NS & NS & NS \\
\hline \multirow[t]{2}{*}{ Performance Status } & 2 vs. $0 / 1$ & $0.425(1.482)$ & $0.114(1.782)$ & $0.026(2.348)$ & NS & NS & NS \\
\hline & $3+$ vs. $1 / 2$ & $0.054(7.452)$ & $0.018(2.864)$ & $9.39 \mathrm{E}-4(3.962)$ & NS & NS & NS \\
\hline CRP** & Continuous & $2.04 \mathrm{E}-5(1.598)$ & $4.74 \mathrm{E}-10(1.732)$ & $9.90 \mathrm{E}-6(1.512)$ & $0.048(1.285)$ & $0.009(1.320)$ & $0.003(1.345)$ \\
\hline Albumin & Continuous & $2.89 E-6(0.854)$ & $1.54 \mathrm{E}-8(0.888)$ & 4.77E-5 (0.923) & $0.001(0.888)$ & $0.003(0.931)$ & $0.027(0.953)$ \\
\hline Platelets & Continuous & $0.392(0.999)$ & $0.091(0.999)$ & $0.021(0.998)$ & NS & $0.008(0.996)$ & $0.092(0.997)$ \\
\hline Neutrophils*** & Continuous & $0.496(1.063)$ & $0.003(1.235)$ & $0.231(1.095)$ & NS & $0.001(1.461)$ & NS \\
\hline SATS & Continuous & $6.95 \mathrm{E}-4(0.727)$ & $7.61 \mathrm{E}-8(0.747)$ & $0.002(0.917)$ & NS & NS & NS \\
\hline Lymphocytes*** & Continuous & $0.897(0.982)$ & $0.164(0.876)$ & $0.052(0.820)$ & NS & NS & NS \\
\hline LDH & Continuous & $0.012(4.279)$ & $5.83 \mathrm{E}-5(7.406)$ & $0.013(2.606)$ & Omitted * & Omitted * & Omitted * \\
\hline NEWS2 & Ordinal & $3.22 \mathrm{E}-4(1.579)$ & $5.05 \mathrm{E}-10(1.546)$ & $0.001(1.158)$ & $0.033(1.248)$ & $2.87 E-6(1.387)$ & NS \\
\hline NLR & Continuous & $0.428(1.075)$ & $1.10 \mathrm{E}-4(1.335)$ & $0.012(1.221)$ & NS & NS & $0.028(1.241)$ \\
\hline CXR & $\begin{array}{l}\text { Consistent with COVID-19 } \\
\text { pneumonia yes vs. no }\end{array}$ & $0.005(3.701)$ & $3.33 \mathrm{E}-10(7.552)$ & $7.12 \mathrm{E}-4(3.116)$ & Omitted * & Omitted * & Omitted * \\
\hline
\end{tabular}

* Omitted due to significant missing data $(>40 \%)$

** $\log 2$ transformed 
$* * * \log 2($ lymphocyte $* 100+1)$

$\mathrm{COPD}=$ Chronic obstructive pulmonary disease, $\mathrm{HTN}=$ hypertension, $\mathrm{CRP}=\mathrm{C}$ reactive protein, $\mathrm{SAT}=$ oxygen saturations, $\mathrm{LDH}=\mathrm{lactate}$ dehydrogenase, NEWS2= National early warning score $2, N L R=$ neutrophil : lymphocyte ratio, $C T=$ Computer tomography, $C X R=$ chest $X-$ ray, $N S=$ not significant $(p$ value $>0.05$ ) 
medRxiv preprint doi: https://doi.org/10.1101/2020.11.30.20239095; this version posted December 3, 2020. The copyright holder for this preprint (which was not certified by peer review) is the author/funder, who has granted medRxiv a license to display the preprint in perpetuity.

Figure 1. Modelling workflow

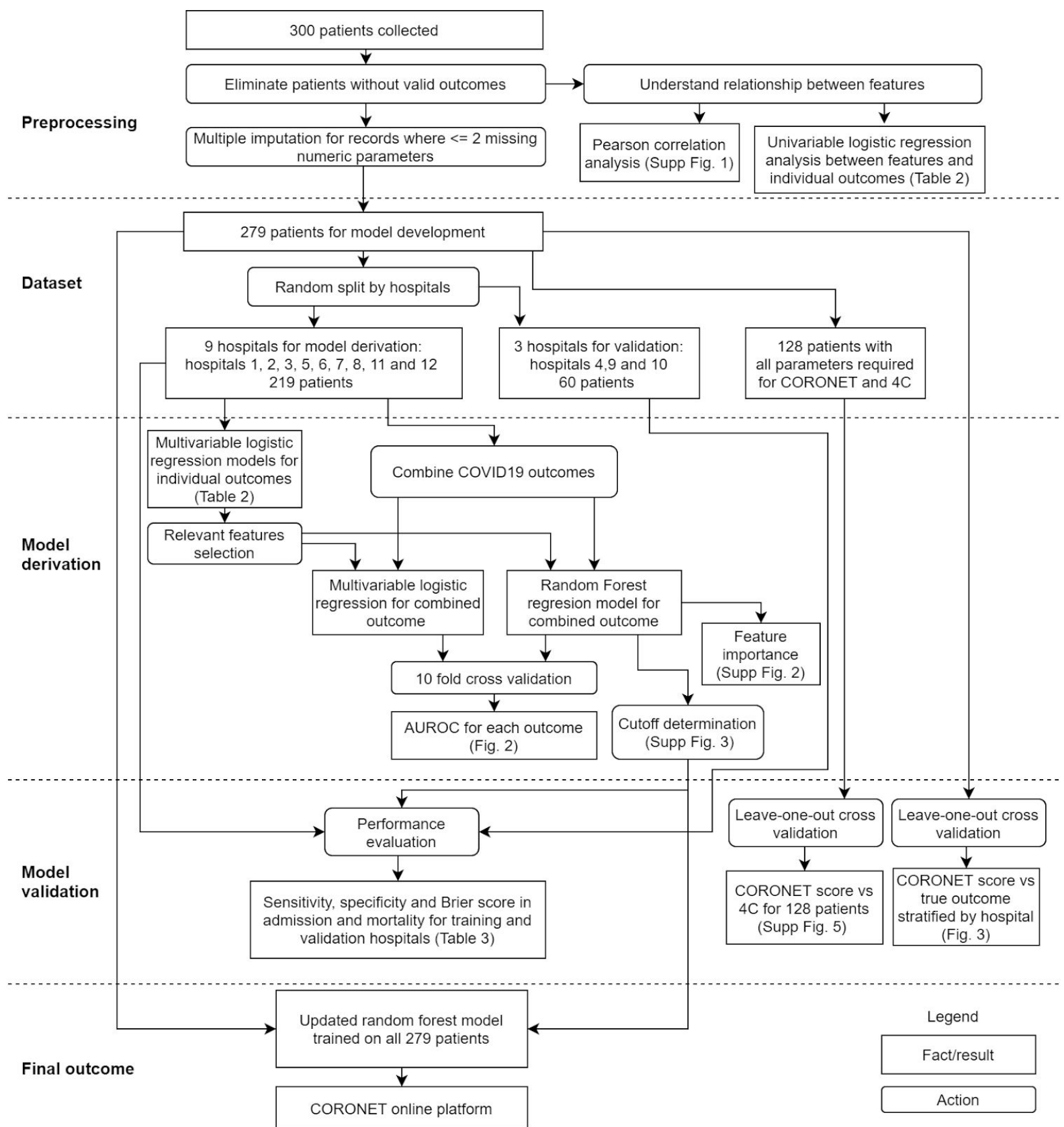


medRxiv preprint doi: https://doi.org/10.1101/2020.11.30.20239095; this version posted December 3, 2020. The copyright holder for this preprint (which was not certified by peer review) is the author/funder, who has granted medRxiv a license to display the preprint in perpetuity.

Figure 2. Performance of the random forest model and the logistic regression model in predicting patient admission and death
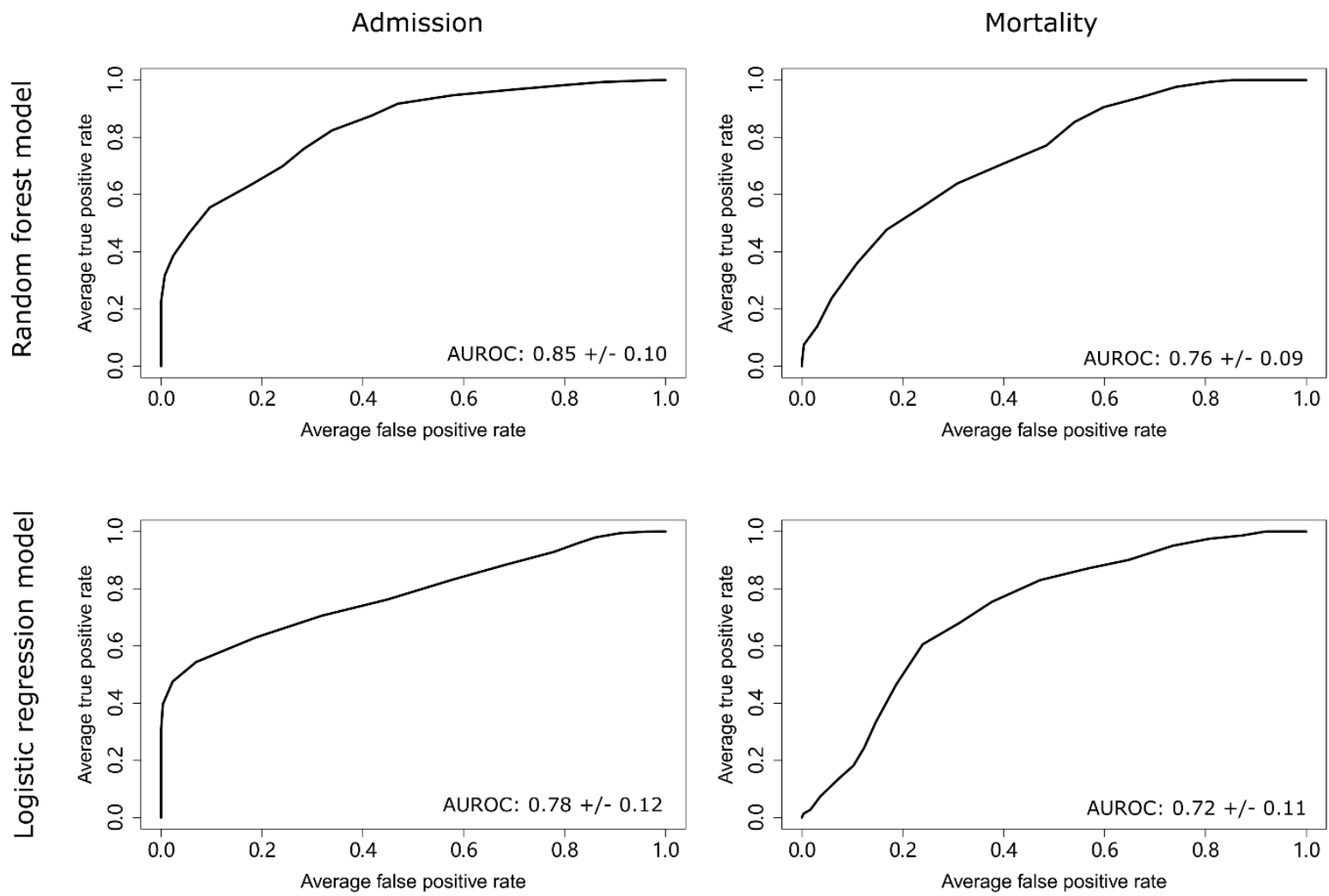
medRxiv preprint doi: https://doi.org/10.1101/2020.11.30.20239095; this version posted December 3, 2020. The copyright holder for this preprint (which was not certified by peer review) is the author/funder, who has granted medRxiv a license to display the preprint in perpetuity.

Figure 3. CORONET score and outcome in cancer patients presenting with CoviD-19 to each hospital in the cohort

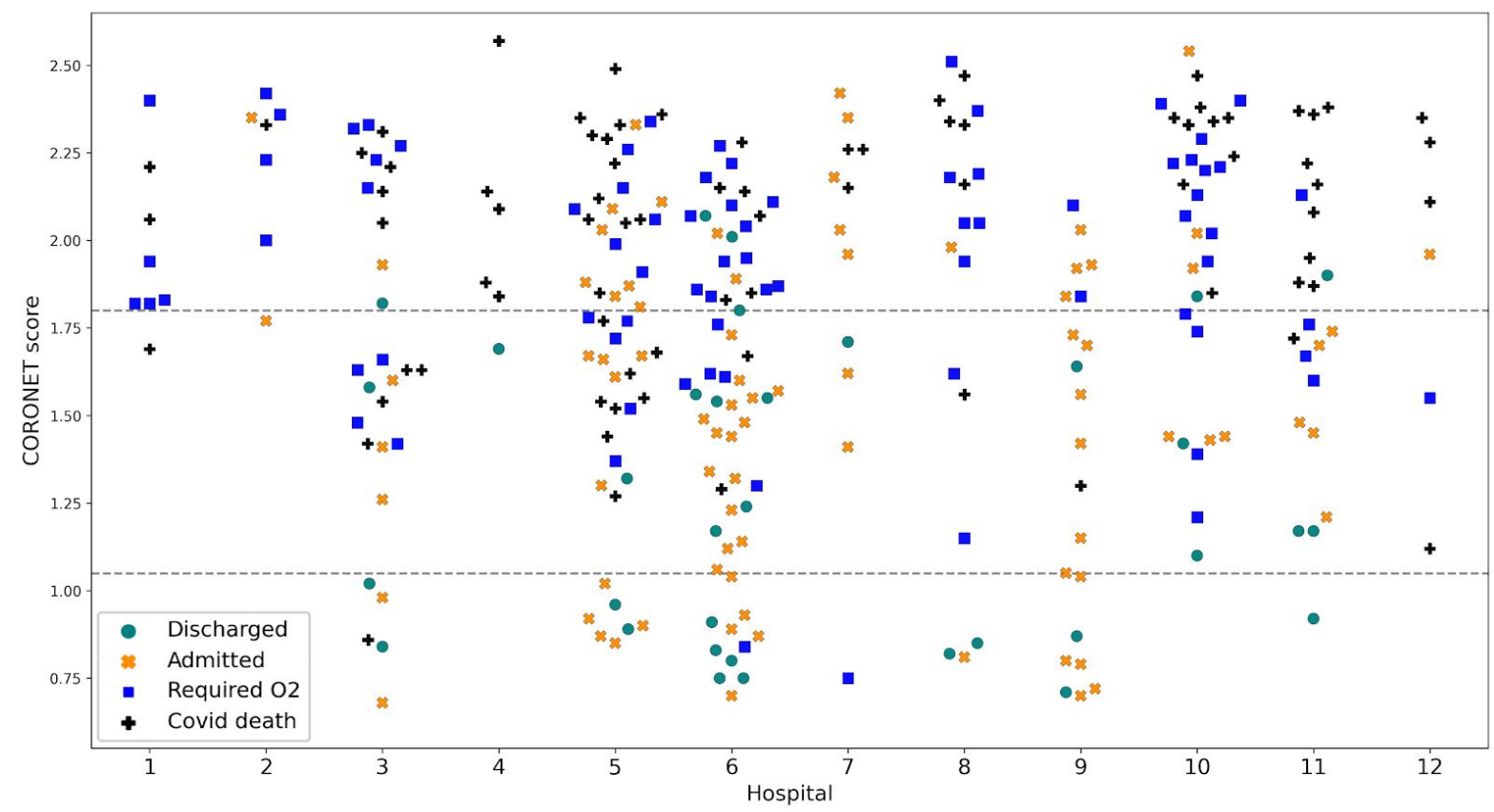

